\title{
A short-term, hydroponic-culture of ginseng results in a significant increase in the anti-oxidative activity and bioactive components
}

\author{
Ji Yun Lee ${ }^{1} \cdot$ Hee Yang ${ }^{1,2} \cdot$ Tae Kyung Lee ${ }^{1}$ Chang Hyung Lee ${ }^{1}$. \\ Ji Won Seo ${ }^{1}$ Jong-Eun $\mathrm{Kim}^{3} \cdot$ Seo Yeong $\mathrm{Kim}^{2} \cdot$ Jung Han Yoon Park ${ }^{1,2}$. \\ Ki Won Lee ${ }^{1,2}$ (D)
}

Received: 31 May 2019/Revised: 20 January 2020/Accepted: 23 January 2020/Published online: 7 March 2020

(C) The Author(s) 2020

\begin{abstract}
Panax ginseng CA Meyer has a variety of biological effects, including antioxidant and antidiabetic activities. Ginseng requires long-term cultivation, but this can be shortened using hydroponic systems to facilitate the commercial development of ginseng as a functional food. However, the characteristics of short-term-cultured ( $<30$ days) hydroponic ginseng (sHCG) are unclear. We investigated the characteristics of 21-day-cultured sHCG compared 5-year-old normally cultured ginseng. The free radical-scavenging activity and total ginsenoside and phenolic contents were significantly higher in sHCG than in normally cultured ginseng. Fifteen ginsenosides were detected in sHCG, and the concentrations of most were higher in shoots than roots. These findings suggest that 21-day-cultured sHCG, due to its enhanced antioxidant activity and higher concentrations of total phenolics and ginsenosides (including $\mathrm{Rd}$ and $\mathrm{Re}$ ), has potential as a functional food.
\end{abstract}

Electronic supplementary material The online version of this article (https://doi.org/10.1007/s10068-020-00735-5) contains supplementary material, which is available to authorized users.

Ki Won Lee

kiwon@snu.ac.kr

1 Department of Agricultural Biotechnology and Research Institute of Agriculture and Life Sciences, Seoul National University, Seoul 08826, Republic of Korea

2 Advanced Institutes of Convergence Technology, Seoul National University, Suwon 16229, Republic of Korea

3 Department of Food Science and Technology, Korea National University of Transportation, Jeungpyeong 27909, Republic of Korea
Keywords Panax ginseng CA Meyer · Hydroponic cultivation · Ginseng · Ginsenosides · Phenolic compounds

\section{Introduction}

Panax ginseng CA Meyer (Korean ginseng) is a perennial plant of the family Araliaceae and has been used as an ingredient in traditional herbal medicines for over 2,000 years, particularly in Asia. Korean ginseng is currently distributed to 35 countries worldwide (Jung et al., 2002).

Ginseng exerts various bioactive effects, including antioxidant and antitumor activities. Prior studies have focused on saponins (ginsenosides), as the primary active ingredients in ginseng, because saponins exert several beneficial effects (Christensen, 2009). The total ginsenoside content is an important determinant of the potency of ginseng. To date, more than 100 ginsenosides have been identified in $P$. ginseng (Shin et al., 2015). most of which belong to one of two major functional types: protopanaxadiol (PPD) and protopanaxatriol (PPT) types. As these two types of ginsenoside exert different physiological effects (Chen et al., 2016), the PPD/PPT ratio is calculated to determine the bioactivity of ginseng (Shan et al., 2014).

The commercial application of ginseng root has been a focus of research. However, other parts of the $P$. ginseng, such as the shoot, which includes the leaf and stem, also contain a variety of ginsenosides ( $\mathrm{Li}$ et al., 1996). Leaves have a higher ginsenoside content than that of primary roots cultivated for the same duration (Kang and Kim, 2016). Most ginsenosides accumulate in leaves during the early growth stages, i.e., the first and second years (Shi et al., 2007). 
Ginseng used for commercial purposes is harvested after cultivation for at least 5-6 years (Soldati and Tanaka, 1984). Recently, a method of short-term cultivation ( $\sim 120$ days) of ginseng seedlings in hydroponic systems has been developed to facilitate the commercialization of P. ginseng as a functional food (Kim et al., 2012). In hydroponic systems, crops are cultivated in nutrient solution instead of soil and in the absence of crop-protective agents such as pesticides. In such systems, it is easier to control key factors in the growth environment including temperature, light intensity, and moisture. Hydroponic cultivation produces higher concentrations of ginsenosides in leaves and roots over a shorter period (Choi et al., 2012). However, although several studies have focused on hydroponic ginseng cultured for 90-120 days, few have evaluated culture durations of less than 30 days. After transplantation of 2-year-old ginseng into a hydroponic system, the ginsenoside content of leaves steadily increased from 7 to 56 days, whereas that in roots increased until 21 days and steeply declined thereafter. Therefore, the optimal cultivation duration for 2-year-old ginseng seedlings after transplantation in hydroponic systems may be less than 30 days (Jang et al., 2018).

We evaluated the antioxidant activity, total ginsenoside content, phenolic content and profiles of 22 ginsenosides in 21-day hydroponically cultured ginseng ( $\mathrm{sHCG}$ ) compared with 5-year-old normally cultured ginseng.

\section{Materials and methods}

\section{Sample preparation}

One-year-old ginseng seedling roots (Panax ginseng CA Meyer) were purchased from Geumsan Ginseng National Agricultural Cooperative Federation (Geumsan, Republic of Korea $[\mathrm{ROK}]$ ) after cultivation in a greenhouse. To obtain sHCG, the seedling roots were transplanted into nutrient baths and cultured in a hydroponic system at $22{ }^{\circ} \mathrm{C}$ under mixed red and blue LED light. A mineral nutrient solution (Farmcraft, Gimpo, ROK) was sprayed onto the roots twice daily. After culturing for 21 days, the sHCG was harvested and used whole or separated into shoots (sHCG-S) and roots (sHCG-R). Normally cultured (5-yearold) ginseng roots were obtained from the Anseong Ginseng National Agricultural Cooperative Federation (Anseong, ROK). The ginseng samples were washed with distilled water and stored at $-70{ }^{\circ} \mathrm{C}$. The samples were lyophilized and ground into powder using a blender (Shinil, Cheonan, ROK). The lyophilized powder was extracted as described previously (Chung et al., 2016a). Briefly, the powder $(0.5 \mathrm{~g})$ was extracted with $50 \mathrm{~mL} 80 \%$ methanol by mixing at $220 \mathrm{rpm}$ at room temperature overnight. The extract was centrifuged at $10,000 \times g$ for $20 \mathrm{~min}$, and the supernatant was filtered through a $0.2 \mu \mathrm{m}$ syringe filter and evaporated. The residue was lyophilized and stored at $-70{ }^{\circ} \mathrm{C}$ until use.

\section{Total antioxidant activity assay}

The total antioxidant activity was evaluated by 1,1-diphenyl-2-picrylhydrazyl (DPPH) radical scavenging assay (Lee et al., 2017). Antioxidant activity is expressed as milligrams of vitamin $\mathrm{C}$ equivalent antioxidant capacity (VCEAC) per $100 \mathrm{~g}$ dry weight.

\section{DCF-DA assay}

Antioxidant activity against hydrogen peroxide $\left(\mathrm{H}_{2} \mathrm{O}_{2}\right)$ induced intercellular ROS was evaluated by DCF-DA assay using $1 \mathrm{mM} \mathrm{H}_{2} \mathrm{O}_{2}$ and $\mathrm{HaCaT}$ cells, as described by Cho et al. (2002) and Yoon et al. (2017) with modifications. ROS accumulation was measured at an emission wavelength of $530 \mathrm{~nm}$ and an excitation wavelength of $485 \mathrm{~nm}$ after incubation for $30 \mathrm{~min}$ in DCF-DA at $25^{\circ} \mathrm{C}$. The fluorescence signal was measured using a microplate reader (Tecan M200 Pro, Männedorf).

\section{Analysis of ginsenosides}

Chromatographic separation was achieved using the LaChromUltra L-2000 U-Series ultra-high-performance liquid chromatograph (ultra-HPLC; Hitachi-High Technologies, Ibaraki-ken, Japan). The HPLC conditions, including the linear mobile phase gradient, column, and detection wavelength, were as described previously (Ha et al., 2013). A total of 22 ginsenosides were analyzed by ultra-HPLC, including 12 PPD types [Rd, Rb2, Rc, Rb1, Rb3, F2, Rg3(S), Rg3(R), K, Rh2(S), Rh2(R), and PPD] and 10 PPT types [Re, Rg1, F1, Rh1(S), Rh1(R), Rg2(S), $\mathrm{Rg} 2(\mathrm{R}), \mathrm{Rf}, \mathrm{PPT}(\mathrm{S})$, and PPT(R)]. The PPD/PPT ratio was calculated as the total PPD content divided by the total PPT content.

\section{Total phenolic content assay}

The total phenolic content was determined by Folin-Ciocalteu assay with modifications (Lee et al., 2017). Activity was expressed as milligrams of catechin equivalents (CE) per $100 \mathrm{~g}$ dry weight.

\section{Analysis of ginsenosides Rd, Rb1, Re and Rg1}

The four major ginsenosides ( $\mathrm{Rd}, \mathrm{Rb} 1, \mathrm{Re}$, and $\mathrm{Rg} 1$ ) were analyzed by high performance liquide chromatography with diode array detector (HPLC-DAD) as described 

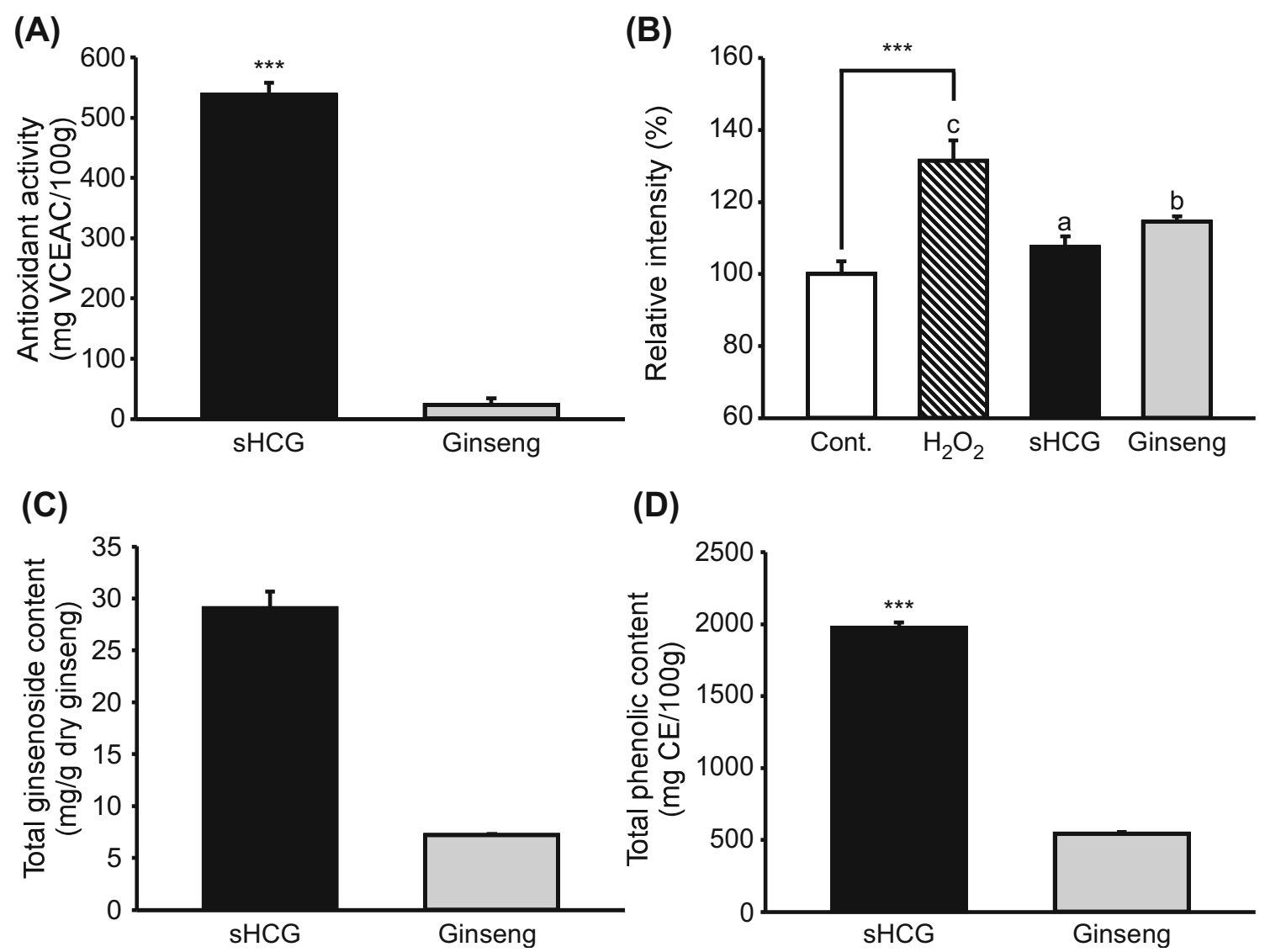

(D)

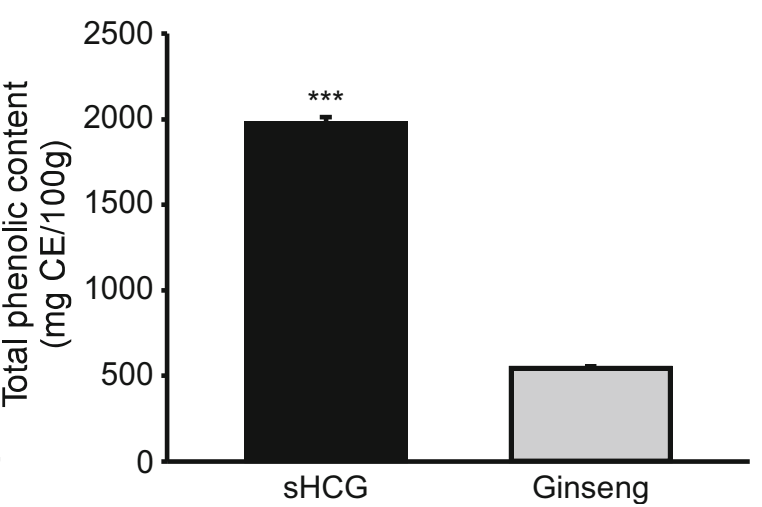

Fig. 1 Characteristics of sHCG and ginseng. 2,2-Diphenyl-1-picrylhydrazyl (DPPH) [if you define one abbreviation then define them all, as done here] antioxidant activity (A), effects of sHCG and ginseng on the intracellular ROS levels of $\mathrm{H}_{2} \mathrm{O}_{2}$-treated $\mathrm{HaCaT}$ cells $(\mathbf{B})$, and

previously (Lau et al., 2003). Briefly, $1 \mathrm{~g}$ sample was extracted with $10 \mathrm{~mL} 70 \%(\mathrm{v} / \mathrm{v})$ aqueous methanol for $2 \mathrm{~h}$. The extracted solution was centrifuged $(850 \times \mathrm{g}, 10 \mathrm{~min}$, $4{ }^{\circ} \mathrm{C}$ ), filtered through a $0.22 \mu \mathrm{m}$ nylon membrane, and analyzed on the Ultimate 3000 HPLC system (Thermo Dionex) using a $4.6 \times 250 \mathrm{~mm}, 5 \mu \mathrm{m}$ Inno C-18 column (Youngjin Biochrom, ROK). The column temperature was maintained at $30{ }^{\circ} \mathrm{C}$. Solvent A was $0.3 \%$ TFA, and solvent $\mathrm{B}$ was acetonitrile. The flow rate was $1 \mathrm{~mL} / \mathrm{min}$, and the following elution gradient was applied: 0-2 $\mathrm{min}, 75 \% \mathrm{~A}$; 2-15 min, 75-60\% A; 15-16 min, 60-0\% A; 16-20 min, 0\% A; 20-21 min, 0-75\% A; 21-28 min, 75\% A. Ginsenosides were detected at $215 \mathrm{~nm}$. The levels of the four ginsenosides in ginseng were quantified using an external standard curve $\left(\mathrm{R}^{2}>0.99\right)$.

\section{Statistical analysis}

Data are expressed as mean \pm standard deviation. The significance of the differences between mean values was determined by Student's $t$ test. A value of $p<0.05$ or $<$ 0.01 was used as the criterion for statistical significance.

the total ginsenoside (C) and total phenolic (D) contents of sHCG and ginseng. Data are means \pm SD $(n=2-4)$. sHCG, short-term hydroponically cultured ginseng

\section{Results and discussion}

\section{Bioactive component contents}

The medicinal effects of ginseng are linked to its antioxidant activity (Fu and Ji, 2003). The free radical-scavenging activity, as determined by DPPH assay, was approximately 23-fold higher for sHCG $(537.3 \pm 21.1 \mathrm{mg} \mathrm{VCEAC/}$ $100 \mathrm{~g}$ ) than normally cultured ginseng $(23.2 \pm 11.1 \mathrm{mg} \mathrm{VCEAC} / 100 \mathrm{~g})$ (Fig. 1A). The intracellular antioxidant activities of sHCG and ginseng were evaluated by DCF-DA. To induce ROS production, HaCaT cells were treated with $\mathrm{H}_{2} \mathrm{O}_{2}(1 \mathrm{mM})$, a free radical (Wu et al., 1996). The ROS level in $\mathrm{H}_{2} \mathrm{O}_{2}$-treated cells was significantly increased, and that of sHCG-treated cells was significantly decreased, compared with ginseng-treated cells (Fig. 1B). These results were similar to those obtained by DPPH assay. Various ginsenosides have antioxidant activity (Sodrul et al., 2018), and thus we examined the total ginsenoside content of sHCG and ginseng. The total ginsenoside content of sHCG (29.0 mg/g dry ginseng) was 

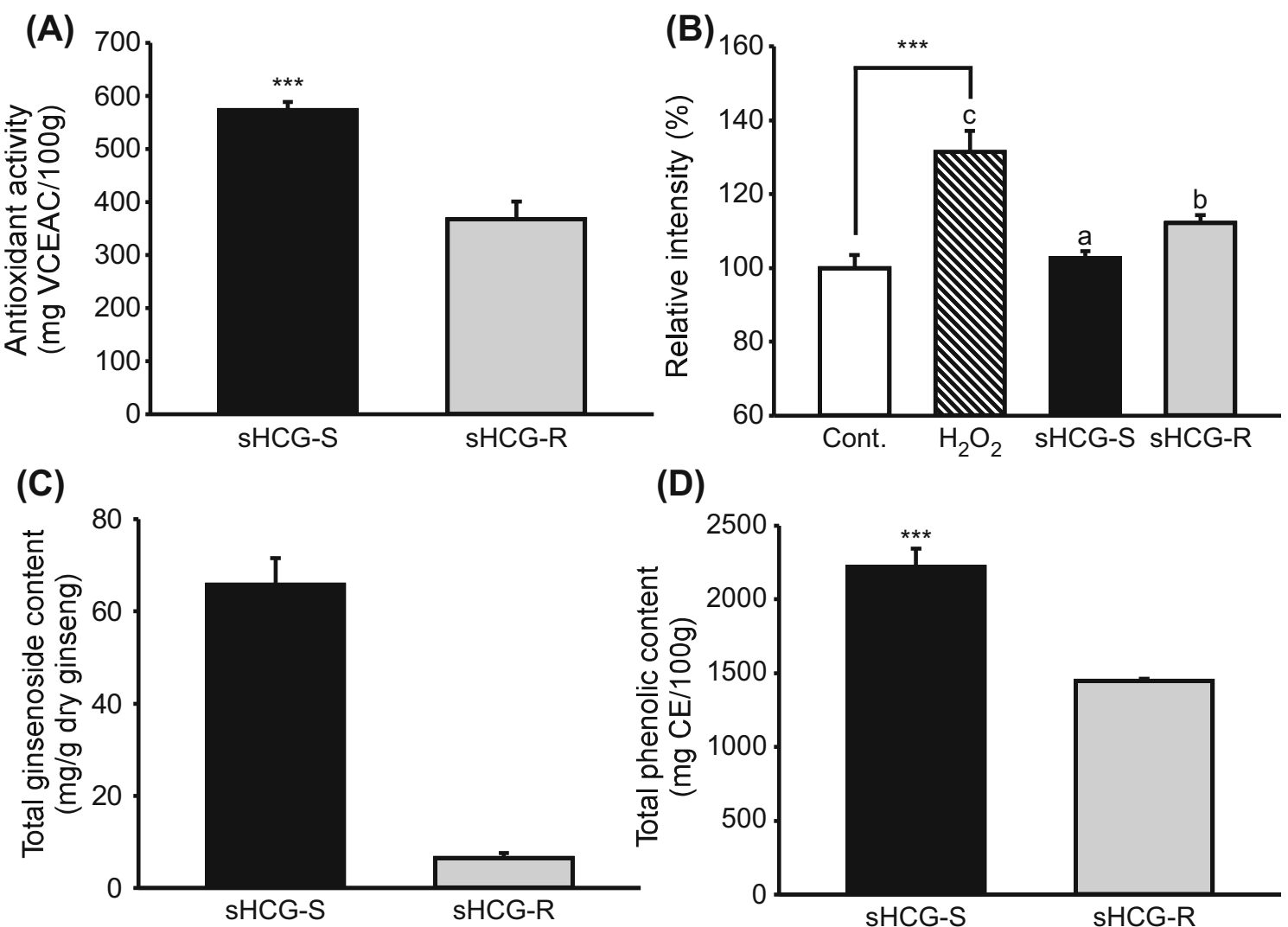

(D)

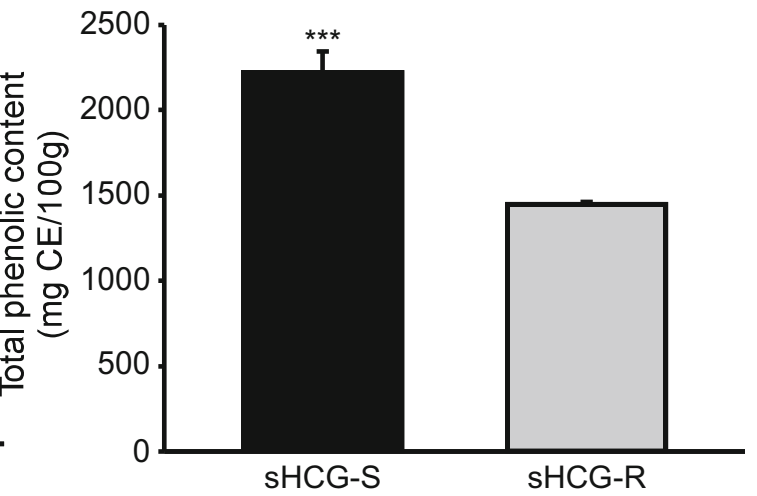

Fig. 2 Characteristics of sHCG-S and sHCG-R. DPPH antioxidant activity (A), effects of sHCG-S and sHCG-R on the intracellular ROS levels of $\mathrm{H}_{2} \mathrm{O}_{2}$-treated $\mathrm{HaCaT}$ cells $(\mathbf{B})$, and the total ginsenoside (C) and total phenolic (D) contents of sHCG-S and sHCG-R. Data are

more than fourfold that of ginseng $(7.2 \mathrm{mg} / \mathrm{g}$ dry ginseng) (Fig. 1C). In addition to saponins, non-saponin compounds including phenolic acids contribute to the antioxidant activity of ginseng (Chung et al., 2016b). Folin-Ciocalteu assays revealed a significantly higher total phenolic content in sHCG $(1975.9 \pm 37.5 \mathrm{mg} \mathrm{CE} / 100 \mathrm{~g})$ than normally cultured ginseng (543.6 $\pm 11.2 \mathrm{mg} \mathrm{CE} / 100 \mathrm{~g})$ (Fig. 1D). These findings suggest that sHCG has stronger antioxidant activity than that of ginseng, which may be attributed to its higher contents of ginsenosides and phenolics.

\section{Bioactive components in SHCG shoots and roots}

After hydroponic cultivation of 1-year-old ginseng seedlings for 21 days, sHCG was divided into sHCG-S and sHCG-R. The dry weight ratio of the two parts was $0.8: 1$ (data not shown). When sHCG-S and sHCG-R were calculated based on this ratio, the result was $29.55 \mathrm{mg} / \mathrm{g}$ dry ginseng. The total amount of sHCG was $29.03 \mathrm{mg} / \mathrm{g}$ dry weight. Therefore, the total amount of sHCG was similar to calculated sHCG-S and sHCG-R. Shoots and roots have means \pm SD ( $\mathrm{n}=2-3)$. sHCG-S, short term hydroponically cultured ginseng shoot; sHCG-R, short-term hydroponically cultured ginseng root

different compositions, including ginsenosides and phenolic compounds (Chung et al., 2016b). The antioxidant activity was significantly higher in sHCG-S $(573.1 \pm 15.2 \mathrm{mg} \mathrm{VCEAC} / 100 \mathrm{~g})$ than in sHCG-R $(367.5 \pm 32.8 \mathrm{mg}$ VCEAC/100 g) (Fig. 2A). The antioxidant activities of sHCG-S and sHCG-R were evaluated by DCF-DA. To induce ROS production, HaCaT cells were treated with $\mathrm{H}_{2} \mathrm{O}_{2}(1 \mathrm{mM})$. The ROS level was significantly lower in HaCaT cells treated with $\mathrm{SHCG}-\mathrm{S}$ than in those treated with sHCG-R (Fig. 2B), similar to the results of the DPPH assays. The total ginsenoside content was approximately 10-fold higher in sHCG-S $(65.7 \mathrm{mg} / \mathrm{g}$ dry ginseng) than in sHCG-R (6.5 mg/g dry ginseng) (Fig. 2C). The total phenolic content was also significantly higher in sHCG-S $(2223.4 \pm 120.1 \mathrm{mg} \mathrm{CE} / 100 \mathrm{~g})$ than in sHCG-R $(1447.4 \pm 13.9 \mathrm{mg} \mathrm{CE} / 100 \mathrm{~g})$ (Fig. 2D). These results indicate that sHCG-S contains more ginsenosides and phenolic compounds than does sHCG-R, leading to higher antioxidant activity. These findings are consistent with previous studies of aged ginseng specimens (Zhang et al., 2014). 


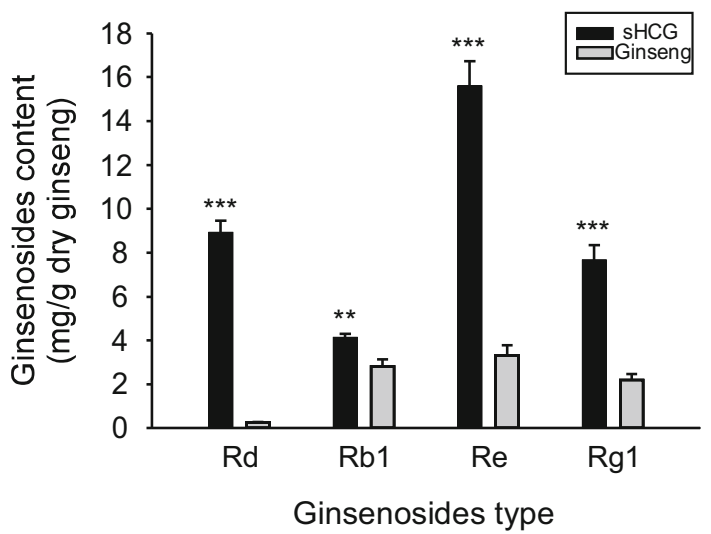

Fig. 3 Contents of four ginsenosides in sHCG and ginseng. Rd, Rb1, $\mathrm{Re}$, and $\mathrm{Rg} 1$ contents of $\mathrm{sHCG}$ and ginseng ( $\mathrm{mg} / \mathrm{g}$ dry ginseng). Data are means $\pm \mathrm{SD}(\mathrm{n}=3)$. sHCG, short term hydroponically cultured ginseng

\section{Profiles of ginsenosides in SHCG, sHCG-S, and SHCG-R}

Of the 22 ginsenosides analyzed, 15 were detected in the original profiling. The Rd content of PPD type and the Re content of PPT type ginsenosides were highest in the sHCG profile (Supplementary data 1). Therefore, we analyzed Rd and $\mathrm{Re}$ together with $\mathrm{Rb} 1$ and $\mathrm{Rg} 1$, marker compounds of ginseng. The levels of these four ginsenosides were significantly higher in sHCG than in ginseng (Fig. 3). The Rd content was 36.4-fold higher in sHCG $(8.89 \mathrm{mg} / \mathrm{g}$ dry ginseng) than ginseng $(0.24 \mathrm{mg} / \mathrm{g}$ dry ginseng) and the Re content 4.7 -fold higher in $\mathrm{sHCG}(15.55 \mathrm{mg} / \mathrm{g}$ dry ginseng) than in ginseng ( $3.30 \mathrm{mg} / \mathrm{g}$ dry ginseng). The $\mathrm{Rb} 1$ and $\mathrm{Rg} 1$ contents were 1.5- and 3.5-fold higher in SHCG (4.10 and $7.61 \mathrm{mg} / \mathrm{g}$ dry ginseng) than in ginseng (2.80 and $2.18 \mathrm{mg} /$ $\mathrm{g}$ dry ginseng), respectively. It is speculated that the ginsenoside components present in sHCG at high levels are determinants of its antioxidant activity; therefore, further studies are warranted.

Here, we report for the first time higher antioxidant capacity and total phenolic and ginsenoside contents in that 21-day cultured sHCG compared with 5-year-old normally cultured ginseng. These findings indicate that shortening the cultivation period can increase the contents of functional compounds, which may be aided by LED light stimulation. Moreover, smart-farming systems have emerged to replace plant factories, permitting automation and optimization of plant growth. Further studies are needed to determine the components responsible for the biological effects of ginseng-both ginsenosides and other compounds, such as phenolics and polysaccharides-and the environmental factors that can be modulated to further increase the contents of these components of interest.
Acknowledgements This work was supported by the Korea Institute of Planning and Evaluation for Technology in Food, Agriculture, Forestry, and Fisheries via the High Value-Added Food Technology Development Program, funded by the Ministry of Agriculture, Food and Rural Affairs (116030-3) and by the BK21 Plus Program of the Department of Agricultural Biotechnology, Seoul National University, Seoul, ROK.

\section{Compliance with ethical standards}

All of the authors complied with the ethical standards.

Conflict of interest None of the authors declare any conflicts of interest.

Open Access This article is licensed under a Creative Commons Attribution 4.0 International License, which permits use, sharing, adaptation, distribution and reproduction in any medium or format, as long as you give appropriate credit to the original author(s) and the source, provide a link to the Creative Commons licence, and indicate if changes were made. The images or other third party material in this article are included in the article's Creative Commons licence, unless indicated otherwise in a credit line to the material. If material is not included in the article's Creative Commons licence and your intended use is not permitted by statutory regulation or exceeds the permitted use, you will need to obtain permission directly from the copyright holder. To view a copy of this licence, visit http://creativecommons. org/licenses/by/4.0/.

\section{References}

Chen XJ, Zhang XJ, Shui YM, Wan JB, Gao JL. Anticancer activities of protopanaxadiol- and protopanaxatriol-type ginsenosides and their metabolites. Evid. Based Complement. Alternat. Med. 2016: 1-19 (2016)

Cho DH, Kang JS, Park, JH, Kim YI, Hahm ES, Lee JC, Yang YH, Jeon JH, Song HK, Park HJ, Kim TS, Pang S, Kim CW, Hwang YI, Lee WJ. The enhanced IL-18 production by UVB irradiation requires ROI and AP-1 signaling in human keratinocyte cell line (HaCaT). Biochem. Biophys. Res. Commun. 298: 289-295 (2002)

Choi SY, Cho CW, Lee Y, Kim SS, Lee SH, Kim KT. Comparison of ginsenoside and phenolic ingredient contents in hydroponicallycultivated ginseng leaves, fruits, and roots. J. Ginseng Res. 36: 425-429 (2012)

Christensen LP. Ginsenosides chemistry, biosynthesis, analysis, and potential health effects. Adv. Food Nutr. Res. 55: 1-99 (2009)

Chung SI, Kang MY, Lee SC. In vitro and in vivo antioxidant activity of aged ginseng (Panax ginseng). Prev. Nutr. Food Sci. 21: 24-30 (2016a)

Chung IM, Lim JJ, Ahn MS, Jeong HN, An TJ, Kim SH. Comparative phenolic compound profiles and antioxidative activity of the fruit, leaves, and roots of Korean ginseng (Panax ginseng Meyer) according to cultivation years. J. Ginseng Res. 40: 68-75 (2016b)

Fu Y, Ji LL. Chronic ginseng consumption attenuates age-associated oxidative stress in rats. J. Nutr. 133: 3603-3609 (2003)

Ha JH, Shim YS, Seo DW, Kim KJ, Ito M, Nakagawa H. Determination of 22 ginsenosides in ginseng products using ultra-high-performance liquid chromatography. J. Chromatogr. Sci. 51: 355-360 (2013) 
Jang IB, Yu J, Suh SJ, Jang IB, Kwon KB. Growth and ginsenoside content in different parts of ginseng sprouts depending on harvest time. Korean J. Med. Crop Sci. 26: 205-213 (2018)

Jung MY, Jeon BS, Bock JY. Free, esterified, and insoluble-bound phenolic acids in white and red Korean ginsengs (Panax ginseng C.A. Meyer). Food Chem. 79: 105-111 (2002)

Kang OJ, Kim JS. Comparison of ginsenoside contents in different parts of Korean ginseng (Panax ginseng C.A. Meyer). Prev. Nutr. Food Sci. 21: 389-392 (2016)

Kim GS, Lee SE, Noh HJ, Kwon H, Lee SW, Kim SY, Kim YB. Effects of natural bioactive products on the growth and ginsenoside contents of Panax ginseng cultured in an aeroponic system. J. Ginseng Res. 36: 430-441 (2012)

Lau AJ, Woo SO, Koh HL. Analysis of saponins in raw and steamed Panax notoginseng using high-performance liquid chromatography with diode array detection. J. Chromatogr. A. 1011: 77-87 (2003)

Lee CC, Dudonné S, Dubé P, Desjardins Y, Kim JH, Kim JS, Kim JE, Park JHY, Lee KW, Lee CY. Comprehensive phenolic composition analysis and evaluation of Yak-Kong soybean (Glycine $\max$ ) for the prevention of atherosclerosis. Food Chem. 234: 486-493 (2017)

Li TSC, Mazza G, Cottrell AC, Gao L. Ginsenosides in roots and leaves of American ginseng. J. Agric. Food Chem. 44: 717-720 (1996)

Shan SM, Luo JG, Huang F, Kong LY. Chemical characteristics combined with bioactivity for comprehensive evaluation of Panax ginseng C.A. Meyer in different ages and seasons based on HPLC-DAD and chemometric methods. J. Pharm. Biomed. Anal. 89: 76-82 (2014)
Shi W, Wang Y, Li J, Zhang H, Ding L. Investigation of ginsenosides in different parts and ages of Panax ginseng. Food Chem. 102: 664-668 (2007)

Shin BK, Kwon SW, Park JH. Chemical diversity of ginseng saponins from Panax ginseng. J. Ginseng Res. 39: 287-298 (2015)

Sodrul IMD, Wang C, Chen X, Du J, Sun H. Role of ginsenosides in reactive oxygen species-mediated anticancer therapy. Oncotarget. 9: 2931-2950 (2018)

Soldati F, Tanaka O. Panax ginseng: Relation between age of plant and content of ginsenosides. Planta Med. 50: 351-352 (1984)

Wu ML, Tsai KL, Wang SM, Wu JC, Wang BS, Lee YT. Mechanism of hydrogen peroxide and hydroxyl free radical-induced intracellular acidification in cultured rat cardiac myoblasts. Circ. Res. 78: 564-572 (1996)

Yoon JJ, Jeong JW, Choi EO, Kim MJ, Hwang-Bo H, Kim HJ, Hong SH, Park C, Lee DH, Choi YH. Protective effects of Scutellaria baicalensis Georgi against hydrogen peroxide-induced DNA damage and apoptosis in $\mathrm{HaCaT}$ human skin keratinocytes. EXCLI J. 16: 426-438 (2017)

Zhang YC, Li G, Jiang C, Yang B, Yang HJ, Xu HY, Huang LQ. Tissue-specific distribution of ginsenosides in different aged ginseng and antioxidant activity of ginseng leaf. Molecules. 19: 17381-17399 (2014)

Publisher's Note Springer Nature remains neutral with regard to jurisdictional claims in published maps and institutional affiliations. 